\title{
Correspondence
}

\section{Consultant psychiatrists in mental handicap}

DeAR SIRS

Dr Singh's letter to the Bulletin (June 1983, 7, 110), suggesting that the proposals of the All Wales Working Party Report would make the role of the psychiatrist in mental handicap less satisfying, prompts me to write to express a differing point of view. I believe that the Working Party that produced this report are to be congratulated for a forward looking, carefully prepared document, embodying the fundamental rights of mentally handicapped people to ordinary health and social services, ordinary housing and an integrated life in the community. Within this report, there is the opportunity to experiment with and evaluate the various ways of meeting the ordinary and special needs of mentally handicapped people in a community setting.

It is well-known that not every mentally handicapped person and his family needs a psychiatrist. Indeed, only a small proportion suffer from pathological stress, mental illness or behaviour disorders for which psychiatric treatment is relevant. In the traditional system of care in the large long-stay mental handicap hospital, many psychiatrists found themselves in a custodial role with the inappropriate task of maintaining abnormally medically-orientated lifestyles and taking responsibility for hundreds of mentally handicapped people, many of whom were mentally healthy. In my experience, it was this anachronistic role often experienced by the trainee on rotational schemes that has in the past reduced the numbers of psychiatrists in mental handicap and this cannot be blamed on the current trends towards community care.

There are now many community mental handicap teams in the country, both in rural and urban settings, whose prime responsibility is the effective delivery of specialist health care, including psychiatry, to mentally handicapped people within a defined catchment area. Within these teams, the consultant psychiatrist and his trainee will experience the opportunity of practising his psychiatric skills learned in general psychiatry in conjunction with the contributions of other members of the team. In this setting, he will find that his skills in diagnosis and treatment of psychiatric disorders are relevant and necessary for a small number of mentally handicapped people and their caring groups.

He will not be burdened with inappropriate clinical responsibility for those who have no need of a psychiatrist.

The principal roles of the psychiatrist in the Mental Handicap Service are:

(1) The prevention of abnormal psychological stress to the handicapped person by the modification of abnormal and stressful life styles.

(2) The diagnosis and treatment of psychiatric illness.
(3) The support of caring groups, including families, in whom there is collective psychopathology.

These roles are much more easily appreciated in a community-based service, complemented by hospital beds available for those who need intensive supervision and treatment (but never to be used as an alternative to home). These beds may well be in a general psychiatric unit, in part of a large hospital where intensive therapeutic intervention has become available or in the smaller specialist health care units that are now developing.

I am optimistic that as more mentally handicapped people remain in ordinary lifestyles, as further community-based teams are set up, as large hospitals move towards closure then the psychiatric component of the service will be more defined, satisfying and attractive.

It is important, however, that trainees at both general and higher professional training have the chance of experiencing such a service rather than the negative experience of being a general practitioner to long-stay wards. The six months' secondment to the psychiatry of mental handicap, now available on many rotational schemes, can be the time when the trainee realizes that the psychiatric needs of mentally handicapped people can be met using psychotherapeutic techniques and all the other interventions practised in general and child psychiatry, or it can be such a negative experience that the trainee feels he can never work with this client group again. Such good experiences as the former will encourage our current trainees to accept joint posts at consultant level or take up consultant posts with a special interest in mental handicap.

The run-down and eventual closure of the larger hospitals therefore provides the challenge to re-define the role of the psychiatrist in the Mental Handicap Service, to work within multidisciplinary teams and to practise psychiatry as taught in any other branch and the custodial role will no longer be relevant. These changes should bring our sub-specialty much closer to others. It has already been my experience that, with such a service, intellectual disability no longer precludes a handicapped person from an anorexia nervosa service, the family therapy clinic or the forensic psychiatry department, for example.

Now that the work on aetiology and primary prevention of mental handicap rests with cytogeneticists, obstetricians, neonatologists, paediatricians and biochemists, there is every chance for the Consultant Psychiatrist in Mental Handicap to concentrate on the 'here and now' and improve the lot of the mentally handicapped person within an integrated setting.

\section{St. George's Hospital Medical School}

London SW17
JOAN BICKNELL 